\title{
Comparison in Bone Density Changes for Two Different Designs in Treatment of Mandibular Bilateral Free End Saddle with Osseointegrated Implants
}

\author{
Seham Ali El-Sayed Sabra ${ }^{1 *}$, Gehan Fekry ${ }^{2}$, Emad Agamy $^{3}$ \\ ${ }^{1}$ Department of Prosthodntic, Al Farabi Colleges for Dentistry and Nursing, Riyadh, Saudi Arabia; ${ }^{2}$ Department of Prosthodntic, \\ Faculty of Oral and Dental Medicine, Minia University, Cairo, Egypt; ${ }^{3}$ Department of Prosthodntic, Faculty of Oral and Dental \\ Medicine, Minia University, Cairo, Egypt
}

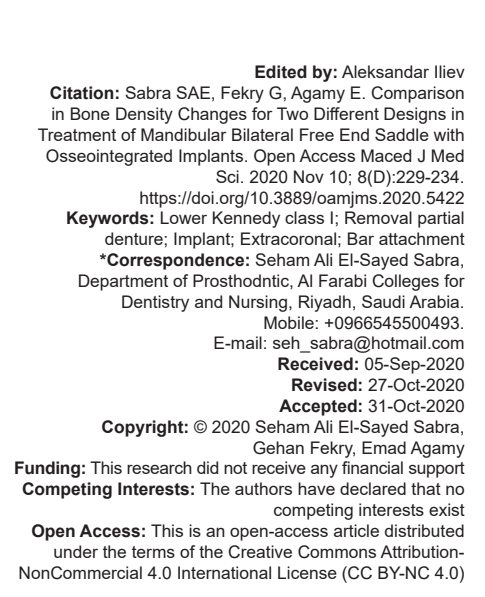

\begin{abstract}
AIM: The aim of this study is to evaluate two different designs in mandibular bilateral free end saddle cases with the use of osseointegrated implants. The designs evaluated were OT-strategy extracoronal attachment and bar attachment. Radiographic evaluation was carried out for implants and natural abutment in terms of bone density.

MATERIALS AND METHODS: This study was conducted on 10 patients with bilateral distal extension area with missing molars bilaterally; the patients were divided into two groups after implant insertion on the second molar area. Group I: Patients received extracoronal attachment distal to the last natural abutment teeth with the construction of metallic removable partial denture (RPD). Group II: Patients received bar attachment with the construction of metallic RPD. Both groups have the maxillary arch edentulous with the construction of complete maxillary dentures within our study. Radiographic evaluation for bone density was done for both groups at the time of prosthesis insertion, 3 , 6 , and 9 months later. A comparison between the two groups regarding each follow-up period was performed by an independent t-test.

RESULTS: Although there were some differences between both designs in the $1^{\text {st }}$-time intervals, generally, there were no significant differences between the two designs all over the 3-time intervals.

CONCLUSION: From the results of this study, it was concluded that: Although there were no significant differences between both designs, bar-attachment showed better results which should be confirmed with more future researches.
\end{abstract}

\section{Introduction}

Although the advent of preventive dentistry has reduced the tooth loss incidence, the number of individuals using some kind of prosthesis is still large, as approximately $73 \%$ of partially edentulous patients report missing molars and premolars, and $40 \%$ have arches classified as Kennedy's Class I [1].

The alveolar ridge is a unique part of the skeleton in the sense that its formation is dependent on tooth eruption. Loss of teeth and the subsequent lack of functional loading of the alveolar ridge through periodontal ligaments lead to alveolar atrophy [2], [3].

Partial tooth loss can be treated using different prosthodontic options, but removable partial dentures (RPDs) are still widely used to replace missing teeth [4], as it has advantages such as the replacement of several teeth in a single prosthesis and it is easier to clean when compared to some fixed prostheses. On the other hand, RPDs can provide limited retention and stability due to their dual support system [5]. Patients may also have some problems such as occlusal disharmony and pain of the soft tissue under the connector or denture base due to the displacement of RPD's distal extension [6].

The double-support system consists of a biological element (abutment teeth and residual ridge) and mechanical element (occlusal and cingulum rests, inner surface of the acrylic saddle, and maxillary major connectors) [7]. In this double-support system, the mechanical elements transmit the masticatory forces to the biological elements that neutralize them. With the masticatory load, the biological element comprising the periodontal ligament of the abutment teeth fulfill the function of converting compressive loads exerted on the tooth into tensile loads, which is considered biologically healthy to maintain the physiological integrity of the bone, considering that the forces are directed along the long axis of the tooth. On the other hand, the alveolar mucosa is not a suitable structure to withstand the occlusal loads due to its resiliency where bone resorption of $0.5 \mathrm{~mm}$ during the first few months of use of the acrylic saddle RPD occurs. Although the resiliency of the oral mucosa absorbs part of the masticatory 
forces, the others are transmitted to the alveolar bone in the form of compression forces which is considered biologically unfavorable for the maintenance of the residual alveolar bone integrity, and it could accelerate the resorption process if uncontrolled [8].

The viscoelastic behavior of the gingiva to vertical load is both compressions of the mucosa and tissue ward movement of the denture base [9]. The mucosa covering the edentulous ridge is much more easily displaced to $0.4-3 \mathrm{~mm}$ and an average of 1.3 $\mathrm{mm}$ than the periodontal ligament of the abutment teeth and has a slower rate of recovery that may extend to several hours [10].

Hence, by applying functional pressure to the distal extension partial dentures, the denture moves toward the mucosal tissues with the greatest movement at the most posterior extent of the denture base and rotation occurs around the fulcrum line connecting the two main occlusal rests, creating damaging forces on the abutment teeth [11].

Free-end RPDs combined with implant retainers are expected to improve retention and stability mainly because of the implants' direct action and their indirect action on bone, providing preservation of the bone level around the implants, especially important in the posterior edentulous areas [4], [12].

\section{Materials and Methods}

Ten partially edentulous patients indicated for implant installation were selected from the Outpatient Clinic, Faculty of Oral and Dental Medicine, Minia University. All patients had Kennedy Class I lower partially edentulous ridges with completely edentulous maxilla to be restored with a complete denture.

\section{Ethical clearance}

All patients participated in the study were informed about the nature of the study and its purpose, agreed to take part in it and write an informed consent reviewed and approved by the research ethics committee of the Faculty of Dentistry Minia University.

Cone-beam computed tomography (CBCT) systems were taken before treatment to evaluate bone density, presence of any anatomical structures, and to determine the appropriate implant angulations.

Reduction of the last 2 abutment teeth on each side was done to receive full veneered porcelain crowns and covered with temporary crowns. Impressions for the upper jaw were done and construction of occlusion blocks to be ready for jaw relation with the lower partial dentures.
Trial setting up of artificial teeth in edentulous areas of mounted upper and lower casts was carried out. Acrylic surgical template was fabricated on the edentulous area of the lower cast. Two screws shaped internal hex titanium implants $(3.9 \mathrm{~mm}$ diameter and $12 \mathrm{~mm}$ length) (Dentis Implants, Dentis Co LTD. One Q-SL. Korea) were inserted bilaterally for each patient in the second molar. Primary stability using the Osstell device (Osstell ISQ, Göteborg, Sweden) was measured for each implant then a healing collar of suitable length was threaded on the fixture. Three days after the fixture installation, the patients were recalled, and another CBCT was made to confirm the angulation of the implant. At this step, patients were divided into two groups.

- Group I: Patients received extracoronal attachment distal to the last natural abutment teeth with the construction of metallic RPD

- Group II: Patients received bar attachment with the construction of metallic RPD

- $\quad$ For Group I: Waxing up for the crowns and extracoronal attachment distal to the last abutment teeth by the help of paralellometer was done, the crowns-attachment assembly was sprued, invested and cast, finished, and polished.

Try-in was done, porcelain was built-on, and porcelain fused to metal restoration was obtained and finally cemented. Rubber base impression was taken for construction of the metal framework (lingual bar, bracing arm on the last abutment tooth, and saddle meshwork). All the steps of metallic partial denture construction were done and the dentures were delivered to patients after occlusal adjustments.

At this step, direct pick up for the metal housing and retentive cap of the extracoronal attachment was done after blocking of undercuts (Figure 1), then finishing for excess resin in the fitting surface and dentures was delivered to the patients

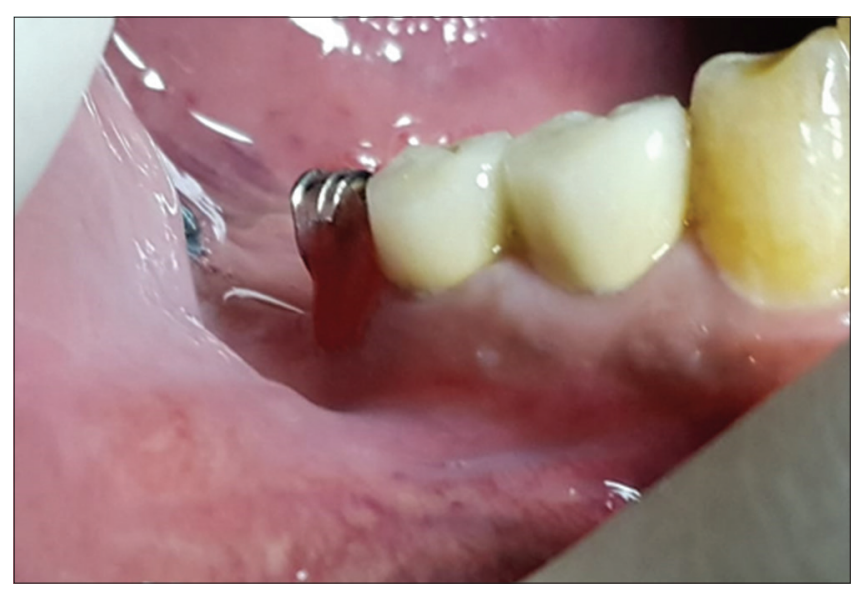

Figure 1: Blocking of undercuts with utility wax under the attachment

- $\quad$ For Group II: A wax pattern was made for implant abutments and natural abutments with using the bar in its resilient form, spruing, investing, and casting. Try in was performed and porcelain was 
built in and final cementation of the assembly was done (Figure 2). Rubber base impression was taken for construction of the metal framework (lingual bar, bracing arm on the last abutment tooth, and saddle meshwork). Then, try in was done and jaw relation with the upper occlusion blocks. Try-in of upper and lower dentures, then delivery with occlusal adjustment.

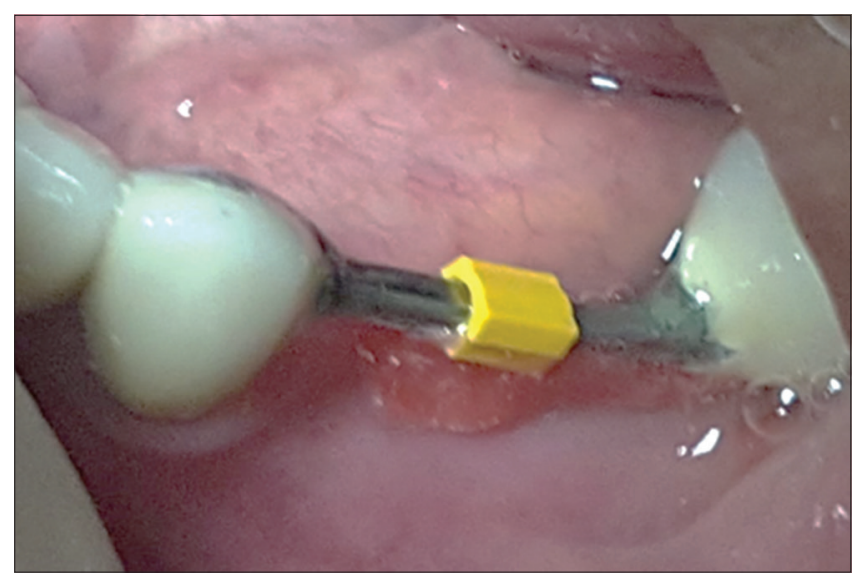

Figure 2: Placing of the clips in its position for direct picking up with blocking of undercuts

At this step, direct pick-up of the retentive clip was done with self-curing acrylic resin after blocking all undercuts. Then, the excess resin was removed and finished. Dentures were delivered to the patient.

Radiographic evaluation was done at four follow-up periods; (0-evaluation), then after 3-, 6- and 9-month intervals, respectively, to evaluate crestal bone density changes of the implant and any peri-implant bone changes with the Digora software (Soredex, Tuusula, Finland). Standardized digital images were obtained following long cone periapical paralleling technique (Rinn Corporation, XCP instrument for extension cone paralleling technique, USA) long cone tube (sixteen inches) of X-ray machine, radiographic template, digital X-ray machine (Kodak 6100, Italy), sensor, and personal computer. Bone density measurements were taken and statistically analyzed.

\section{Results}

\section{Bone density changes around peri-implant bone for both designs}

The mean values of bone density for OT-Strategy attachment type were $129.95 \pm 22.453$, $117.68 \pm 13.168,140.56 \pm 15.572$, and $150.76 \pm 18.691$ at insertion, 3 months, 6 months, and 9 months follow-up period, respectively. While for bar attachment type were $122.43 \pm 26.541,121.90 \pm 20.306,135.49 \pm 20.691$, and $150.49 \pm 14.246$ at insertion, 3 months, 6 months, and 9 months follow-up period, respectively (Figure 3 ).

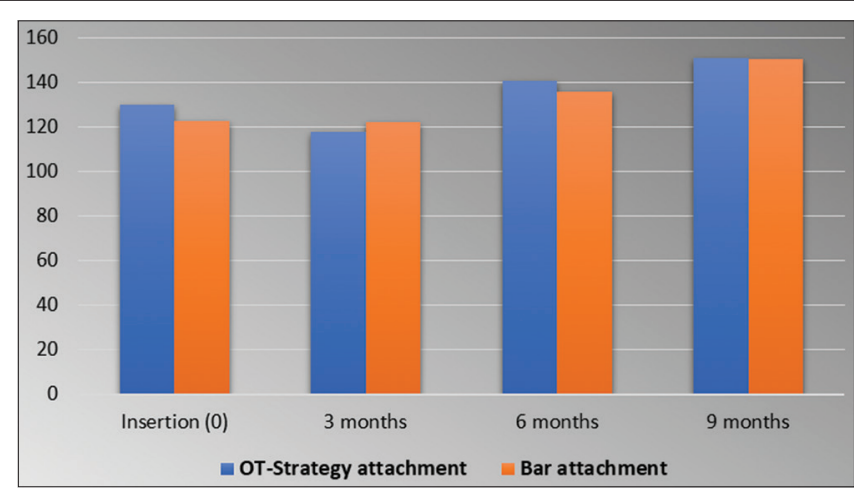

Figure 3: Mean and standard deviation values of peri-implant bone density of OT-strategy extracoronal attachment and bar attachment

\section{Bone density changes around the natural abutment teeth for both designs}

The mean values of bone density for OT-strategy attachment type were $191.15 \pm 21.078$, $102.14 \pm 9.763,143.52 \pm 18.103$, and $156.20 \pm 18.609$ at insertion, 3 months, 6 months, and 9 months follow-up period, respectively. While for bar attachment type were $142.12 \pm 18.148,137.07 \pm 20.138,142.12 \pm 18.248$ and $156.96 \pm 14.136$ at insertion, 3 months, 6 months, and 9 months follow-up period, respectively (Figure 4).

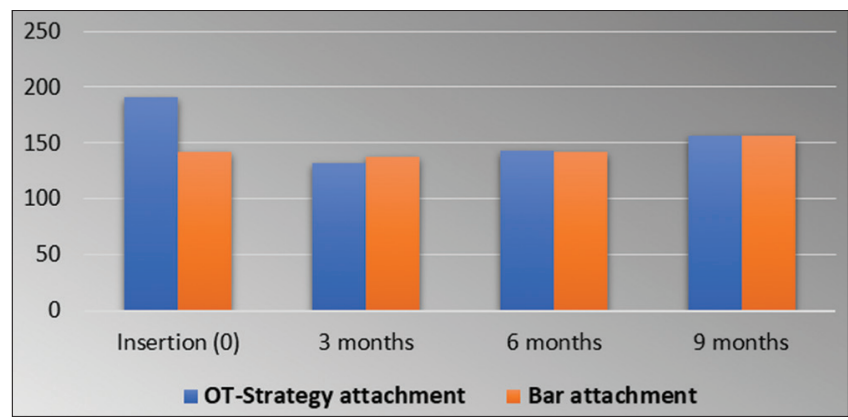

Figure 4: Mean and standard deviation values of abutment bone density of OT-strategy extracoronal attachment and bar attachment

The effect of time on the mean values of peri-implant bone density for both groups (OT-strategy and bar attachment)

The results of peri-implant bone density measured for both types of attachments (OT-strategy and bar attachment) along the follow-up intervals, that is, the calculated differences between each visit and the previous one showed no significant difference between both designs in time intervals between 3,6 , and 9 months, respectively (Figure 5).

The effect of time on the mean values of the natural abutment bone density for both groups (OT-strategy and bar attachment)

The results of peri-implant bone density measured for both types of attachments (OT-strategy 


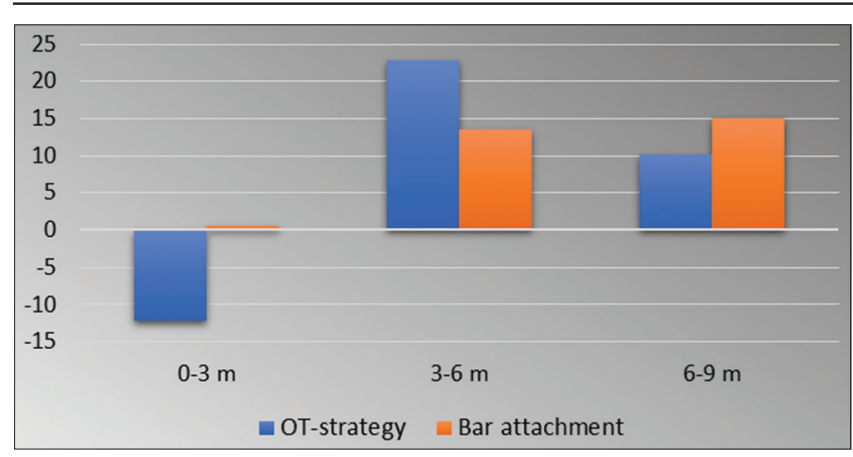

Figure 5: Effect of time on mean values of peri-implant bone density for OT-strategy extracoronal attachment and bar attachment

and bar attachment) along the follow-up intervals showed no significant difference between both designs (Figure 6).

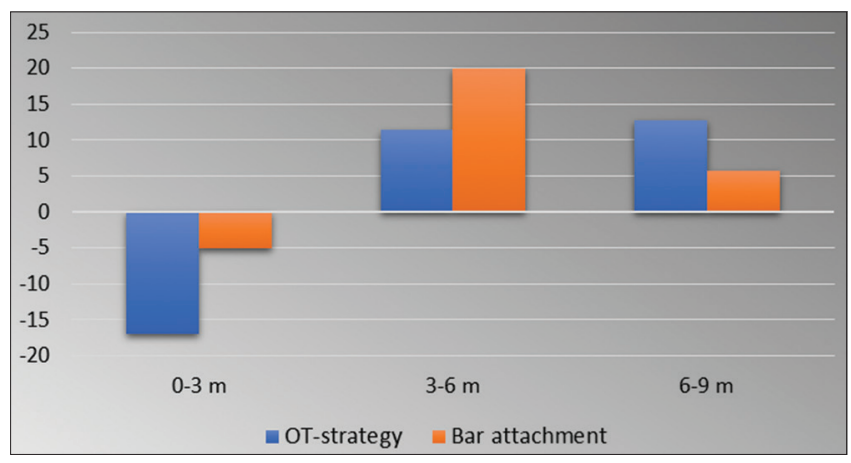

Figure 6: Effect of time on mean values of abutment bone density for OT-strategy extracoronal attachment and bar attachment

\section{Discussion}

Mandibular bilateral distal extension cases were selected in this study as they are more common than the maxillary ones due to the general pattern of tooth loss. Furthermore, mandibular distal extension cases are considered the most difficult to receive satisfactory and comfortable dentures due to support problems and smaller denture base area in relation to the functional load [13]

Implant-supported mandibular distal extension base partial dentures opposed by new maxillary complete dentures with bilateral balanced occlusion was suggested. This creates occlusal harmony, standardizes the amount of force applied on the lower prostheses from the opposing occlusion, improves load distribution, and avoids potentiating parafunctional activity which increases bone loss around implants.

This treatment option can successfully prevent the occurrence of combination syndrome by stabilizing the posterior occlusion [14]. The bilateral balanced occlusal scheme is recommended in this case, as the vertical load will be favorable [15].

The site of implant installation was the second molar area, as it has been stated that implants should be located as distally as possible to provide maximum support for the prosthesis [16].

Rigid lingual bar major connector was designed to enhance the stability of the prosthesis, more comfortable and esthetic than other types. It is recommended as well when resilient attachments are used in distal extension cases [17].

Thayer and Caputo [18] studied the various tissue bar attachments and concluded that the hader bar produced less torquing force and distributed the forces more evenly between the posterior edentulous area and the contralateral abutments in comparison with the other tissue bar designs. It is also economic and easily available compared to other bar attachments. It has the advantage of adjusting the vertical height on the master cast before casting depending on the availability of the vertical space. Furthermore, the plastic sleeves can be easily replaced if required later [19].

Splinting of the abutments on the distal extension side was done by full coverage fixed permanent type of splints as recommended by many authors [20], [21].

The importance of splinting implants with a cross-arch prosthesis after placement to achieve a favorable load distribution has been discussed in several studies [22], [23]. To gain a better understanding of the role of implant splinting, loading of freestanding and splinted implants was compared in a finite element analysis [24]. In their model, splinted implants showed greatly reduced stresses in the bone tissue surrounding the implants, especially in bone of lower density, compared to freestanding implants.

Extracoronal attachment was used in this study as it has been shown that attachment retained cast partial dentures gives better comfort, function, esthetics, less adjustments, abutment teeth protection, easy to clean, and easily used by the patient and provides excellent retention and distribution of occlusal forces to the supporting structures [25].

OT-strategy attachments are the only attachments of this type to have parallel support under the sphere that automatically aligns the retentive caps, which is an important factor in prosthesis insertion and prevents the risk of wear to the spheres. The reduced dimension of this attachment permits them to be used in very small areas, so they are perfect to be used in removable prostheses [26].

In general, with the follow-up period, both the natural abutment tooth and implant showed changes both clinically and radiographically in the OT-strategy extracoronal attachment group and bar group. These changes seem to be logic as it is well-known that after insertion of any prosthesis in the patient's mouth, the oral environment is altered and changes in the rate of plaque formation occur with its sequelae as stresses transmitted to the investing structures [27], [28]. 
Although bone density changes were insignificant with time in both study groups, there was an increase in both groups in time intervals, which indicates favorable bone reaction, as bone respond positively to the applied load by building additional support through the arrangement of its trabecular pattern and heavy cortical lamina dura or negatively by attaining the opposite reaction. It was recognized that increase in the working load results in an increase of bone mass without exceeding the biological loadbearing capacity of the alveolar bone [29], [30].

Although there were no significant differences between the extracoronal attachment and the bar attachment, the initial bone resorption of the bar attachment was less, this could be explained by a study done by Mishra et al. [31]. Who used two canines as abutments splinted together with a bar and found that it is more advantageous than using the individual abutments separately. This is due to the splinting effect of the bar. Both teeth become firm and are safer abutments. It also reduces the torquing of the remaining root structure because the crown-root ratio is decreased.

According to Hanif et al. [32], even with increased demand for implants in the dental market, several biological and mechanical complications do exist. However, despite the already well-researched, successful, evidence-based osseointegration concept, the association between implants and RPDs still requires longitudinal studies to prove their efficiency and long-term safety for wider use.

\section{Conclusion}

From the results of this study, it was concluded that: Although there were no significant differences between both designs, bar-attachment showed better results which should be confirmed with more future researches.

\section{References}

1. Gonçalves TM, Campos $\mathrm{CH}$, Garcia RC. Implant retention and support for distal extension partial removable dental prostheses: Satisfaction outcomes. J Prosthet Dent. 2014;112(2):334-9. https://doi.org/10.1016/j.prosdent.2013.11.004 PMid:24513426

2. Araújo MG, Lindhe J. Dimensional ridge alterations following tooth extraction. An experimental study in the dog. J Clin Periodontol. 2005;32(2):212-8. https://doi. org/10.1111/j.1600-051x.2005.00642.x

PMid:15691354

3. Chappuis V, Engel O, Reyes M, Shahim K, Nolte LP, Buser
D. Ridge alterations post-Extraction in the esthetic zone: A 3D analysis with CBCT. J Dent Res. 2013;92 (12 Suppl):195S-201. https://doi.org/10.1177/0022034513506713

PMid:24158340

4. Gates WD, Cooper LF, Sanders AE, Reside GJ, De Kok IJ. The effect of implant-supported removable partial dentures on oral health quality of life. Clin Oral Implants Res. 2012;25:207-13. https://doi.org/10.1111/clr.12085

PMid:23278481

5. De Freitas RF, De Carvalho Dias K, Da Fonte Porto Carreiro A Barbosa GA, Ferreira MA. Mandibular implant-supported removable partial denture with distal extension: A systematic review. J Oral Rehabil. 2012;39(10):791-8. https://doi. org/10.1111/j.1365-2842.2012.02326.x

PMid:22882547

6. Sato M, Suzuki Y, Kurihara D, Shimpo H, Ohkubo C. Effect of implant support on mandibular distal extension removable partial dentures: Relationship between denture supporting area and stress distribution. J Prosthodont Res. 2013;57(2):109-12. https://doi.org/10.1016/j.jpor.2013.06.002

PMid:23582267

7. Campos $\mathrm{CH}$, Gonçalves TM, Garcia RC. Implant-supported removable partial denture improves the quality of life of patients with extreme tooth loss. Braz Dent J. 2015;26(5):463-7. https:// doi.org/10.1590/0103-6440201300097

PMid:26647929

8. Neppelenbroek KH. Biomechanics of removable partial dentures. Pro-dental prosthesis. Upgrade Prog. 2010;2:39-139.

9. Prasad S, Monaco EA. A modified treatment approach for fabricating a mandibular distal-extension partial denture: A clinical report. Quintessence Int. 2010;41(3):185-9.

PMid:20213017

10. Tumrasvin W, Fueki K, Ohyama T. Factors associated with masticatory performance in unilateral distal extension removable partial denture patients. J Prosthodont. 2006;15(1):25-31. https://doi.org/10.1111/j.1532-849x.2006.00065.x

PMid: 16433648

11. Nakamura Y, Kanbara R, Ochiai KT, Tanaka Y. A finite element evaluation of mechanical function for 3 distal extension partial dental prosthesis designs with a 3-dimensional nonlinear method for modeling soft tissue. J Prosthet Dent. 2014;112(4):972-80. https://doi.org/10.1016/j.prosdent.2014.03.011 PMid:24819523

12. Rodrigues RC, Faria AC, Macedo AP, De Mattos MD, Ribeiro RF. Retention and stress distribution in distal extension removable partial dentures with and without implant association. J Prosthodont Res. 2013;57(1):24-9. https://doi.org/10.1016/j. jpor.2012.07.001 PMid:23200090

13. Lammie GA, Laird WR. Osborne and Lammie's Partial Dentures. $5^{\text {th }}$ ed. Oxford, London: Blackwell Scientific Publication; 1986. p. 289-307.

14. Maeda Y, Sogo M, Tsutsumi S. Efficacy of a posterior implant support for extra shortened dental arches: A biomechanical model analysis. J Oral Rehabil. 2005;32(9):656-60. https://doi. org/10.1111/j.1365-2842.2005.01478.x PMid:16102078

15. Omura AJ, Latthe V, Marin MM, Cagna DR. Implant-assisted removable partial dentures: Practical considerations. Gen Dent. 2016;64(6):38-45. PMid:27814254

16. Jacobs R, Quirynen M, Bornstein MM. Neurovascular disturbances after implant surgery. Periodontol 2000. 2014;66(1):188-202. https://doi.org/10.1111/prd.12050 
PMid:25123768

17. Carr A, Brown D. McCracken's Removable Partial Prosthodontics. $12^{\text {th }}$ ed. St Louis, Missouri: Elsevier; 2011. p. 231-41.

18. Thayer $\mathrm{HH}$, Caputo AA. Photoelastic stess analysis of overdenture attachments. J Prosthet Dent. 1980;43(6):611-7. PMid:6989977

19. Pigozzo MN, Mesquita MF, Henruiqes GE. The service life of implant-retained overdenture attachment systems. J Prosthet Dent. 2009;102(2):74-80. https://doi.org/10.1016/ s0022-3913(09)60112-8

PMid:19643220

20. El Charkawi H, El Wakad M. Effect of splinting on load distribution of extracoronal attachment with distal extension prosthesis in vitro. J Prosthet Dent. 1996;76(3):315-22. https:// doi.org/10.1016/s0022-3913(96)90178-x

PMid:8887807

21. Kanathila $H$, Doddamani $M$, Pangi $A$. An insight into various attachments used in prosthodontics: A review. Int J Appl Dent Sci. 2018;4(4):157-60.

22. Tarnow DP, Emtiaz S, Classi A. Immediate loading of threaded implants at stage 1 surgery in edentulous arches: Ten consecutive case reports with 1- to 5-year data. Int J Oral Maxillofac Implants. 1997;12(3):319-24.

PMid:9197096

23. Maló $P$, Rangert $B$, Dvärsäter $L$. Immediate function of Brånemark implants in the esthetic zone: A retrospective clinical study with 6 months to 4 years of follow-up. Clin Implant Dent Relat Res. 2000;2(3):138-46. https://doi.org/10.1111/j.1708-8208.2000. tb00004.x PMid:11359258

24. Bergkvist G, Simonsson K, Rydberg K, Johansson F, Dérand T. A finite element analysis of stress distribution in bone tissue surrounding uncoupled or splinted dental implants. Clin Implant Dent Relat Res. 2008;10(1):40-6. https://doi. org/10.1111/j.1708-8208.2007.00059.x

PMid:18254739

25. Shakeel SK. Removable prosthesis using extra coronal precision attachment. Gulf Med J. 2013;2(S1):S126-9.

26. Rhein 83 USA Inc.; 2009. Available from: http://www.Rheinusa. com. [Last accessed on 2020 May 20]

27. Nada MA, Gharrphy S, Badawy HS. A two year longitudinal study on the effect of removable partial denture design on the health of the remaining teeth. Egypt Dent J. 1987;33(1):85-95.

28. Von Wowern N, Gotfredsen K. Implant-supported overdentures, a prevention of bone loss in edentulous mandibles? A 5-year follow-up study. Clin Oral Implant Res. 2001;12(1):19-25. https://doi.org/10.1034/j.1600-0501.2001.012001019.x PMid:11168267

29. Buser D, Schenk RK, Steinemann S, Fiorellini JP, Fox CH, Stich $\mathrm{H}$. Influence of surface characteristics on bone integration of titanium implants. A histomorphometric study in miniature pigs. J Biomed Mater Res. 1991;25(7):889-902. https://doi. org/10.1002/jbm.820250708

PMid:1918105

30. Murphy WM. Clinical and experimental bone changes after intraosseous implantation. J Prosthet Dent. 1995;73(1):31-5. PMid:7699596

31. Mishra R, ShivrayanA, Jain S, Mehta S. Fabrication ofbar-retained tooth-supported mandibular overdenture. Int J Oral Health Sci. 2014;4:37-41. https://doi.org/10.4103/2231-6027.151624

32. Hanif A, Qureshi S, Sheikh Z, Rashid H. Complications in implant dentistry. Eur J Dent. 2017;11(1):135-40. https://doi. org/10.4103/ejd.ejd_340_16

PMid:28435381 